\title{
Design of Elastic Screw Fasteners under Tensile Load
}

\author{
Edward. E. Osakue ${ }^{1} \&$ Lucky Anetor ${ }^{2}$ \\ ${ }^{1}$ Department of Industrial Technology, Texas Southern University, Houston, Texas, USA \\ ${ }^{2}$ Department of Mechanical Engineering, Nigerian Defence Academy, Kaduna, Nigeria \\ Correspondence: Edward. E. Osakue, Department of Industrial Technology, Texas Southern University, Houston, \\ Texas, USA. E-mail: osakueee@tsu.edu
}

Received: May 15, 2017

Accepted: May 29, 2017

Online Published: May 31, 2017

doi:10.5539/mer.v7n1p13

URL: https://doi.org/10.5539/mer.v7n1p13

\begin{abstract}
This paper presents an equivalent stress approach in the design of screw fasteners under tensile load. Design equations are formulated for sizing and verifying screw fastener selection. It considers axial tensile, direct shear, bending, and torsional stresses and combines them as appropriate into equivalent or effective stresses. The equivalent or effective stresses are compared with screw fastener material strength capabilities such as proof, yield, fatigue, and tensile strengths for failure assessment. Design factors are derived for assessing design adequacy of the screw fasteners. For elastic screw fasteners, these stresses must each be in the elastic range for the screw material. When the load is removed, elastic screw fasteners regain their original size and shape, behaving like springs. Two illustrative design examples are used to demonstrate both design verification and sizing tasks. Design verification was performed in the first example and the static yield design factors are found to be 0.77 and 0.68 for the preload and service load, respectively. These values are less than unity, representing a case of under-design in static yield failure modes. Without changing the specification of the screw fastener, the preload tension was reduced by $62.76 \%$, and the static yield design factors changed to 1.42 and 1.12 for the preload and service load, respectively. This shows that the under-design condition resulted from high preload tension. When the screw pitch is changed from coarse to fine series, the design factors are worse off in fatigue stress resistance but indicated some improvement in static stress resistance. This suggests that fine pitch threads is not better than coarse pitch threads in fatigue stress capacity when direct shear and bending stresses are considered in Example 1. Both design sizing and verification are performed in Example 2. Design sizing suggests a screw fastener $(\mathrm{M} 10 \times 1.5)$ of slightly larger size than the previous solution $(\mathrm{M} 8 \times 1.25)$. Design verification indicates the previous solution and new solution has a minimum static yield design factor of 0.93 and 1.09, respectively for the service load. This suggests that the screw fastener of the previous solution may yield in service, if implemented. The new solution has a higher design factor in this failure mode and presents less risk of failure. From the illustrative examples presented, it seems that ignoring direct and bending stresses in screw fastener design can lead to under-design in some failure modes.
\end{abstract}

Keywords: Elastic, Screw fastener, Design, Static yield, Fatigue, Failure, Strength

\section{Introduction}

A screw is an externally threaded mechanical element. An external thread is a helical ridge on the outside surface of a cylinder or a cone. An internal thread as in a nut, is a helical groove on the inside surface of a hollow cylinder or cone. Screw fasteners are used to hold two or more parts together in a detachable joint. The common types of screw fasteners are cap screws, bolts, and studs. Screw fastener sizes have been standardized nationally by the American National Standards Institute (ANSI) and internationally by the International Standardization Organization (ISO). ISO standards are the most popular, being the first choice all over the world.

Selection of screw fasteners depends on many factors that include service load, operating temperature, cost, weight, corrosion resistance, magnetic properties, assembly conditions, expected life, etc. The stiffness of screw and clamped members determine the proportion of imposed load carried by the threads. The screw stiffness factor for screw joints is in the range of 0.15 to 0.4 (Schmid, Hamrock, \& Jacobson, 2014). When gaskets are used, it may be confined as in O-ring applications or unconfined as in cylinder heads of automobiles. In confined gasket applications, the gasket stiffness may be assumed negligible and the joint may be considered as a hard joint so that the clamped components stiffness is used in design analysis. In unconfined gasket applications, the clamped component stiffness may be assumed negligible compared to that of the gasket. In this case, the stiffness of clamped members may be 
approximated by the stiffness of the gasket and the joint may be considered as soft. In hard joint, most of the service load is taken by the clamped members but in a soft joint, the screw carries most of the service load. Clearly it is desirable to have hard joints so as to minimize screw load and size.

Many screw fasteners are subjected to tensile load in service, for instance; screws used in cylinder head covers, pressurized vessels, eyebolts, turnbuckles, flange coupling bolts, etc. Screws under bending load such as some foundation and bracket bolts are also loaded in tension. For screws loaded in shear (common in structural design), it is good design practice to avoid the shear plane passing through the threads. Dowel pins in close-fits are preferred for shear loads in machinery assembly. The screw is sometimes made of a stronger material than the nut in a bolted joint. This promotes local yielding in the nut threads when the fastener is tightened and thus improves thread fit and better load sharing among the threads. In a joint, the screw fastener is in tension while the nut is in compression so that the pitch of the screw tends to increase while the nut pitch tends to decrease. This deformation of the screw and nut threads helps to relieve subsequent threads below the first of the imposed load. Thus the first few threads in the engagement normally carry a higher proportion of the service load. Experiments suggest that the first thread carries $38 \%$, the second carries 25\% and the third carries 15\% of the imposed load (Budynas \& Nissbett; Gope, 2014).

When in service, many screw fasteners are subjected to vibrations that are transferred to the screw threads. For proper functioning, appropriate preload tension must be applied. The preload induces tension on the screws but imposes compressive load on the clamped components. High clamping force prevents fluids from leaking by containing fluid pressure, resisting shear loads through interfacial friction, and absorbing most of any fluctuating dynamic load. Creep, corrosion, wear, vibrations, etc. slowly reduced the elastic deformation from preload with time. Elevated temperature or cyclic temperature fluctuations may accelerate the loss of preload. The loss of preload can potentially reduce fatigue resistance as well as cause separation of joint. Dismantling and re-assembling increases chances of loosening for joints. It is common practice to specify re-tightening schedule for screw fasteners in order to maintain proper preload (Collins, Busby \& Staab, 2010).

Screw fasteners can fail in several modes but the dominant stress in a screw under tension is tensile. Other potential failure modes of screws are stripping shear failure at the thread roots, and fatigue failure. When screw and nut are made of the same material and the nut height is at least half the screw diameter, stripping failure is unlikely (Collins, Busby \& Staab, 2010). Standard nuts have a height of approximately 0.875 times screw diameter and thick nuts have heights approximately equal to the screw diameter. These proportions practically eliminate stripping failure of threads. Since there is no relative motion when screw fasteners are in service, bearing stress is generally neglected and crushing stress should be considered instead. Experience shows that $90 \%$ of screw joint failures are due to fatigue (Berezovsky, Chernilevsky \& Petrov). Fatigue failure analysis of screws indicates that $15 \%$ of failures occur at the fillet under the head, $20 \%$ occur at the end of threads on the shank, and $65 \%$ occur in the threads that are in contact with the nut (Budynas \& Nissbett, Bhandari, 2010). About $85 \%$ of screw failures are associated with the threads in engagement and the crack originates at a thread corner (Zahavi, 1992). Inadequate design consideration, material problems, insufficient preload, loosening, and excessive loads can all contribute to screw fastener fatigue failure (Hudgins \& James, 2014). If the preload tension is not correct, the joint could fail in several ways such as fatigue fracture, vibration loosening, stress corrosion cracking, and hydrogen embrittlement (FEDS, 2009). Higher preload results in decreased cyclic stress amplitude; especially, when the external load is below the preload tension value. To minimize chances of loosening, the highest preload tension possible should be used, up to but not exceeding the yield strength of the screw fastener material. Screw fasteners failure can lead to disastrous consequences and substantial financial loss. (Hudgins \& James, 2014).

In current screw fastener design practice, attention is largely on the axial tensile stress in a screw and sometimes, the torsional stress from the preload is considered. Bending and shear stresses are rarely considered and when done, they are treated mostly independently. Considering these stresses independently simplifies analysis but the combined effect is unknown. Neglecting these stresses means the actual operating stresses are under estimated in screw fastener design. A consideration of equivalent stresses can help determine the effect of combined axial tensile, bending, and shear stresses. This presents the possibility of being able to assess the combined effect on potential failure modes. The approach ensures that all stress types are properly considered in screw fastener design. This study seeks to incorporate these stresses into equivalent or effective stresses in screw fastener design since in practice they all contribute to screw joint failures. Models for equivalent and or effective stresses are developed for screw preload, maximum service load, static, dynamic fatigue, and crushing failure modes.

\section{Design Basis}

In screw fastener design, the external axial load is normally assumed to act through the center of the screw while the nut and screw engage at the threads. The resistive contact forces therefore act on the threads which are located off the 
screw center. Physically, the screw threads may be construed as cantilever beams carried on the root diameter of the screw fastener. Assuming the resistive force acts at the pitch circle diameter of the screw, the thread is then subjected to both bending and direct shear loads at the root diameter of the screw or nut. Direct axial tensile stress is generated by the central load on the screw fastener, so the shear and bending stresses are additional. In the current design of screws, the direct shear and bending stresses caused by the contact load on threads are often neglected. If these were considered and estimated, certainly they will increase the equivalent stress on the screw threads. If the increase is sufficiently high, then the screw may fail earlier than expected. Another type of stress of relevance is the torsional shear stress which is imposed during pre-loading at the time of assembling. Though this stress is released after pre-load, it increases the imposed stress on the screw thread at preloading. Due to the caution and rate of loading during preloading, the screw joint may be considered to be under static load. From the above consideration, the torsional stress is in addition to the enumerated stresses and should be taken into account in screw design. Crushing stress is generally neglected but a quantitative estimate should be informative.

\subsection{Equivalent Cylinder}

It is found experimentally that the tensile stress area of a screw can be related to its pitch and root diameters (Budynas \& Nissbett). Thus we may associate the tensile stress area with a fictitious equivalent diameter which can be used in design analysis. This diameter is the average of the pitch and root diameters of the thread. The tensile stress area, thread base shear area, and thread base section modulus can be evaluated using the diameter of the fictitious cylinder. This type of abstraction is not new in design. An example is the use of fictitious cylinders of equivalent diameters for gears referred to the pitch point. Figure 1a shows a physical screw with pertinent design parameters while Figure $1 \mathrm{~b}$ is the equivalent cylinder.

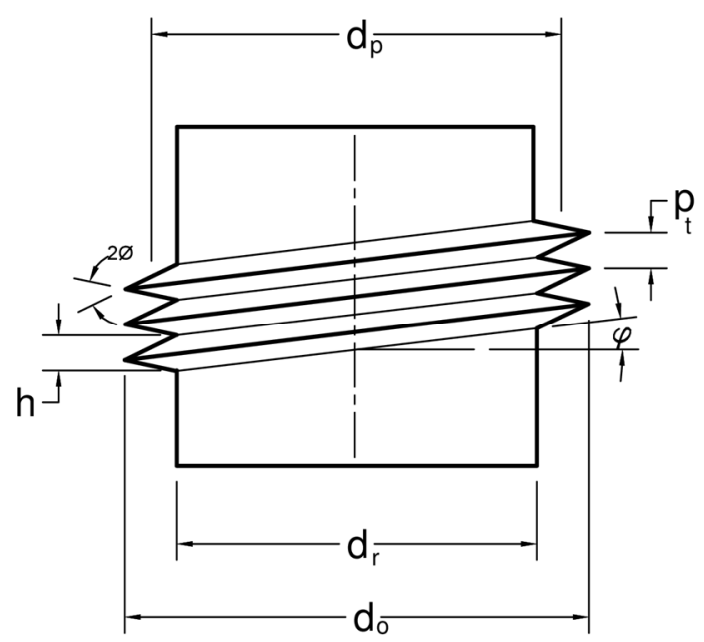

a: External screw thread

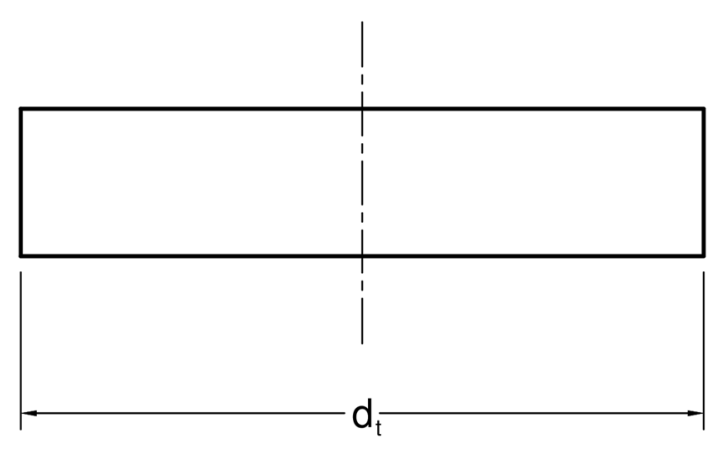

b: Equivalent cylinder

Figure 1. Screw fastener and equivalent cylinder

Referring to Figure 1a, and for metric threads (Budynas \& Nissbett; Childs, 2004):

$$
\begin{aligned}
& d_{p}=d_{o}-0.649519 p_{t} \\
& d_{r}=d_{o}-1.226869 p_{t}
\end{aligned}
$$

Referring to Figure 1b, the tensile stress diameter is taken as the mean of $d_{p}$ and $d_{r}$. From Eqs. (1) and (2):

$$
d_{t}=d_{o}-0.938194 p_{t}
$$

The land of metric thread profile is $0.25 p_{t}$, so the thread root thickness is obtained as:

$$
h=0.25 p_{t}+2 \times 0.5 \times\left(d_{o}-d_{r}\right) p_{t} \tan \varphi
$$

Referring to Figure 1, for metric threads, $2 \varphi=60^{\circ}$ or $\varphi=30^{\circ}$. Hence: 


$$
h=0.958333 p_{t}
$$

Single start threads are used in most screws, so the lead angle and lead angle factor are, respectively:

$$
\phi=\tan ^{-1}\left[\frac{p_{t}}{\pi d_{p}}\right] \quad \mu_{0}=\tan \phi
$$

\subsection{Thread Loading in Screw Joints}

Figure $2 \mathrm{a}$ shows the loads on a screw joint in service after it is preloaded. The external load, in general, has a minimum and a maximum value. This naturally creates a fatigue load situation and it is little surprising that fatigue failure is the most common failure mode in screw joints. The effective load on the threads is influenced by the deformation of the screw and the clamped parts. The deformation of individual parts depends on its stiffness.

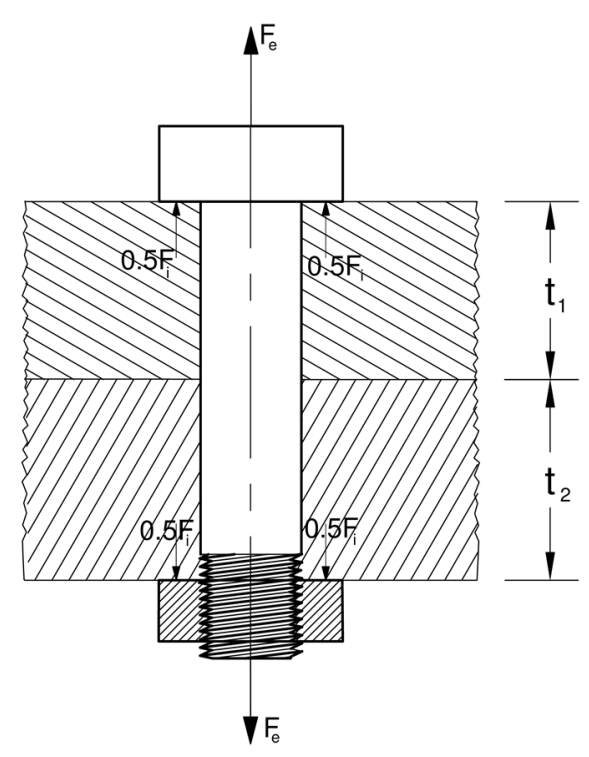

a) Loads on joint

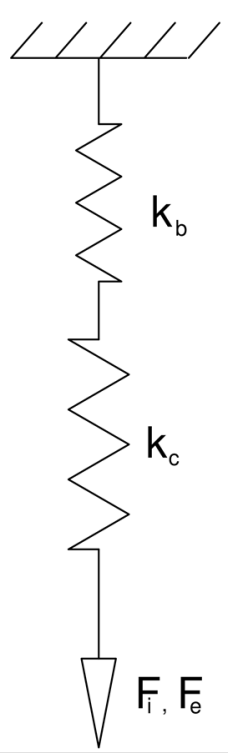

b) Screw joint model

Figure 2. Screw joint

Figure $2 \mathrm{~b}$ shows the conceptual model of the screw joint consisting of two springs in a series arrangement: one for the screw fastener and the other for the clamped parts. The stiffness of individual clamped part and that of the screw fastener have to be estimated in order to evaluate the load transferred to the threads. For the stiffness of the clamped members, the work of Shigley has gained popular acceptance (Budynas \& Nissbett; Gope, 2014; Schmid, Hamrock, \& Jacobson, 2014). He formulated a compression pressure cone stiffness model for each clamed part in a joint and a half-cone-angle of $30^{\circ}$ is commonly assumed. The clamped parts are considered as springs in series so that their combined stiffness is evaluated as $k_{c}$. The screw fastener stiffness $k_{b}$, is evaluated with a different model. The load transferred to the screw threads depends on the relative stiffness of the screw fastener to that of the clamped parts and is called the screw stiffness factor, $c_{b}$. It is given by:

$$
c_{b}=\frac{k_{b}}{k_{b}+k_{c}}
$$

If joint bodily separation is to be prevented, then the range of preload tension is:

$$
F_{e}\left(1-c_{b}\right)<F_{i}<\alpha_{p} A_{t} S_{p}
$$

The parameter $\alpha_{p}$ is taken as 0.75 for fatigue loading or reused joints and 0.9 for static loading or permanent joints (Childs, 2004; Budynas \& Nissbett), but they are prescribed arbitrarily. 
The loads transferred to the threads are:

$$
F_{b \max }=F_{i}+c_{b} F_{e} \quad F_{b \min }=F_{i}+c_{b} F_{e}^{\prime}
$$

The loads above are summarized by:

$$
F_{b}=F_{m}+F_{a}
$$

where:

$$
\begin{aligned}
& F_{m}=F_{i}+c_{b} F_{e m} \quad F_{a}=c_{b} F_{e a} \\
& F_{e m}=0.5\left(F_{e}+F_{e}^{\prime}\right) \quad F_{e a}=0.5\left(F_{e}-F_{e}^{\prime}\right)
\end{aligned}
$$

Figure 3a shows the contact forces on the first and second threads of a screw and nut when in engagement. Subscript 1 identifies the first thread, while subscript 2 identifies the second thread. During pre-tensioning, the forces acting come from the preload tension. When the screw fastener is in service, the contact forces come from the service load. As indicated in Figure 3b, thread forces act at the pitch radius of the thread (Schmid, Hamrock \& Jacobson, 2014). The force $F_{1}$ is the load carried by the first thread and the second thread carries the force $F_{2}$. Assuming the threads are in good contact, the force $F_{2}$ on the second screw thread is transferred to the first screw thread by the nut thread.
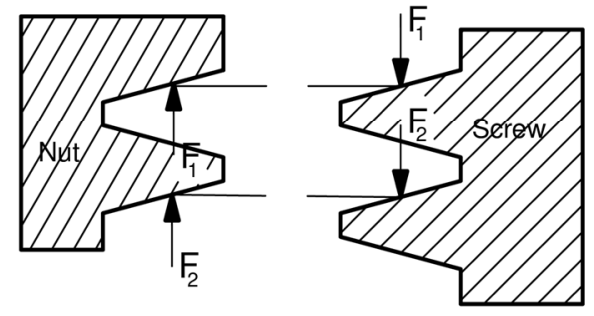

a: Contact forces between 1 st and 2nd threads

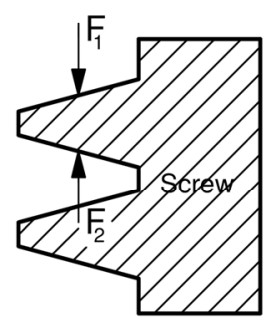

b:Resultant contact force on 1st thread

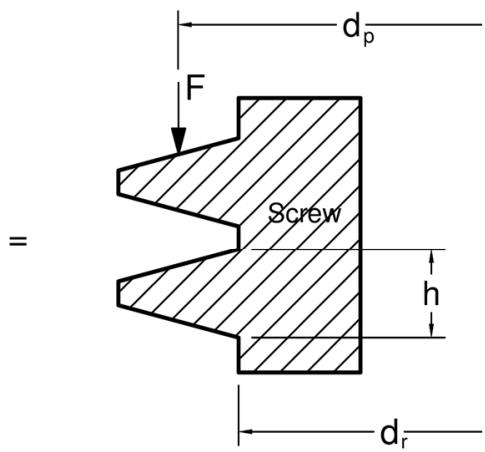

Figure 3. Thread load in shear and bending

Based on experiments and after preload: $F_{1}=0.38 F_{i}$ and $F_{2}=0.25 F_{i}$ and in service $F_{1}=0.38 F_{b}$ and $F_{2}=0.25 F_{b}$ [Budynas \& Nissbett, Gope, 2014). Only the first two threads need be considered since the others carry lower proportions of the load on the joint. From Figure 3b, the resultant static contact forces on the first thread after preload and in service are respectively:

$$
F=F_{1}-F_{2}=0.13 F_{i} \quad F=F_{1}-F_{2}=0.13 F_{b}
$$

Similarly, the resultant fatigue mean and alternating contact forces on the first thread in service are respectively:

$$
F=F_{1}-F_{2}=0.13 F_{m} \quad F=F_{1}-F_{2}=0.13 F_{a}
$$

\subsection{Assumptions}

The screw thread form is complicated from the point of analysis (Budynas \& Nissbett). The local deformations at the screw and nut threads under load further complicate the analysis. Therefore, very accurate estimation of stresses in screw fasteners is a real challenge. While relatively simple stress capacity model may be used to estimate initial size of a screw, during design verification, the screw must be assessed against static yield and fatigue resistances with more accurate capacity models. To simplify the design analysis of screw fasteners, the following assumptions are made: 
1) Screw material is ductile

2) Hooke's law applies

3) Tensile diameter is used to estimate section shape properties

4) Preload should prevent joint separation

5) Mean load is static load

6) Stress concentration is unity for static load for ductile materials

7) Gerber fatigue failure rule applies

\section{Design Sizing of Elastic Screws}

The objective in design sizing is to obtain an initial size of a component. This size is used to initiate design optimization in the design verification task. In preliminary design calculations, simplifying assumptions are made to help initiate the normal iterative design process. A reasonable estimate of size in design sizing task should result in fewer iterations during design verification (Bausbacher \& Hunt, 1993). Design sizing should be based on the most significant failure mode of a component in order to obtain a reasonable initial size (Osakue, Anetor \& Odetunde, 2015). The external load applied to screws in a joint leads to tensile, shear, and bending stresses in the thread. But the predominant stress in screws under tensile load is the tensile stress. The shear and bending stresses caused by the imposed load makes initial sizing rather complicated, so they may be ignored at design sizing. The worst case in the screw loading is when the external load is high enough to separate the joint. At that point the load on the screw is equal to the external load. Assuming the external load is applied to the equivalent screw cylinder, the tensile stress on it is:

$$
\sigma_{t}=\frac{F_{e}}{A_{t}}
$$

It is reported that $90 \%$ of screw joint failures are due to fatigue (Berezovsky, Chernilevsky \& Petrov, 1988). Since fatigue failure is most common in screw joints, it seems reasonable to account for stress concentration in the predominant axial tensile stress above. A stress concentration factor may be included in Eq. (15) for this purpose. Assuming linear-elastic deformation of the screw fastener, the stress must be in the elastic range: that is, at most equal to the proof strength. Therefore:

$$
\sigma_{t}=\frac{k_{\sigma} F_{e}}{A_{t}} \leq S_{p}
$$

For rolled threads, the stress concentration factor is taken as 2.2 for M5.8 screw material grade and below and 3.0 for M6.6 and above. For cut threads, the stress concentration factor is taken as 3.0 for M5.8 and below and 3.8 for M6.6 and above (Budynas \& Nissbett). Mass produced external threads are usually rolled and gives smoother thread finish and better fatigue resistance. Specialty threads are made by cutting, usually on a lathe or similar machine-tools. It is usually safe to assume that threads have been rolled, except otherwise specified (Schmid, Hamrock \& Jacobson, 2014). In fatigue design, the surface finish influence on fatigue strength is incorporated in the stress concentration factor. A fatigue size factor should be taken into account in determining the fatigue strength of screw fastener.

The root stress concentration factor for cut and rolled threads may be estimated, respectively as:

$$
k_{\sigma}=1.0914 \times \ln \left(S_{u t}\right)-3.678 \quad k_{\sigma}=0.8731 \times \ln \left(S_{u t}\right)-2.942
$$

For sizing purposes and from Eq. (16):

$$
A_{t} \geq \frac{k_{\sigma} F_{e}}{S_{p}}
$$

Eq. (18) is a simplified screw fastener design sizing model which does not require evaluating the stiffness of the screw fastener $\left(k_{b}\right)$ and clamped parts $\left(k_{c}\right)$ or the screw stiffness factor $\left(c_{b}\right)$. Values of $A_{t}$ for standard screw fasteners are listed in tables in design textbooks and handbooks, so estimate from Eq. (18) can be used to select appropriate size. Alternatively, the screw diameter may be estimated and used for selection. That is:

$$
A_{t}=\frac{\pi}{4} d_{t}^{2} \quad d_{t} \geq \sqrt{\frac{4 A_{t}}{\pi}}=\sqrt{\frac{4 k_{\sigma} F_{e}}{\pi S_{p}}}
$$

For coarse metric screws of nominal size in the range of $10 \mathrm{~mm}$ to $48 \mathrm{~mm}$, on the average: 


$$
d_{o} \approx 1.135 d_{t}
$$

\section{Design Verification of Elastic Screws}

The objective in design verification is to assess the adequacy of a design. Based on the result(s) of design sizing, the designer(s) have size(s) which can be used to estimate stresses or other performance capacities. The performance capacity result(s) can then be judged for acceptability. In the case of screws, different stress capacity models may be investigated. As mentioned previously, tensile stress, shear stress, and bending stress are generated by the loads imposed on them. The tensile stress is assumed uniform on the screw fastener and the direct shear stress is also assumed uniform at the root base. Bending and torsional stresses vary linearly from the center line of the screw fastener. The critical design point is the root of the first thread which bears the highest proportion of the imposed load.

\subsection{Static Yield Resistance}

Static tensile failure is most likely during installation when the screw is preloaded for application. During preloading, direct axial tensile, bending, direct shear and torsional stress are created but the torsional stress is released after assembly. During preload or setup, the screw joint may be viewed as loaded by a static force, $F_{i}$.

\subsubsection{Axial Tensile Stress}

The static axial stress after preload is:

$$
\sigma_{z}=\frac{F_{i}}{A_{t}}
$$

\subsubsection{Direct Shear Stress}

The maximum direct shear stress for the first thread is from Eq. (13a):

$$
\tau_{s}=\frac{0.13 F_{i}}{A_{s}}
$$

$$
A_{s}=b h
$$

$$
b=\pi d_{t}
$$

\subsubsection{Bending Stress}

From Figure 3b, the moment arm of the thread load is:

$$
l_{a}=\frac{d_{p}-d_{r}}{2}
$$

The maximum bending stress for the first thread is from Eq. (13a):

$$
\sigma_{b}=\frac{0.13 F_{i} l_{a}}{Z_{x}} \quad \sigma_{b}=\frac{0.13 F_{i}\left(d_{p}-d_{r}\right)}{2 Z_{x}}
$$

where:

$$
Z_{x}=\frac{b h^{2}}{6}
$$

\subsubsection{Preload Torsional Stress}

For proper functioning of screw fasteners, appropriate preload tension must be applied. For critical joints, it is obligatory to control the preload tension on screw joints (Korsakov, 1987). High preload is desirable because the problem of joint separation is largely eliminated. It is better to use highly stressed small screw than lightly stressed large screw because the stiffness of the small screw is less (Gope, 2014). The minimum tightening force must ensure that the joint can operate without separation (Korsakov, 1987). The maximum tightening force must produce a stress less than the yield strength of the screw fastener material. It is common practice to specify an initial preload torque that produces a stress of about $75 \%$ of the yield strength or $85 \%$ of the proof stress (Collins, Busby \& Staab, 2010). Generally, the preload tension should produce a stress in the range of $50 \%$ to $80 \%$ of the yield strength of screw fastener material (Korsakov, 1987).

When estimating the preload torque, all thread forces are assumed to act at the pitch radius of the thread and the collar force acts at the midpoint of the collar surface (Schmid, Hamrock \& Jacobson, 2014). The preload torque may be estimated as: 


$$
T_{i} \approx K_{i} F_{i} d_{o}
$$

where $K_{i}=\frac{d_{p}}{2 d_{o}}\left[\frac{\mu_{o}+\mu_{t e}}{1-\mu_{o} \mu_{t e}}\right]+0.625 \mu_{c} \quad$ and $\mu_{t e}=\frac{\mu_{t}}{\cos \varphi}$

An experiment with unlubricated screw yielded a coefficient of variation (cov) of $15 \%$ for the initial tension torque and $9 \%$ cov for lubricated screw (Budynas \& Nissbett). Variations of $\pm 25 \%$ in preload torque are routinely experienced (Gope, 2014). The accuracy of applied initial tension torque can be increased by determining the thread friction coefficient experimentally. In that case, a torque deviation of $\pm 10 \%$ may be achieved (Korsakov, 1987). On the average, $\mu_{t} \approx \mu_{c} \approx 0.15$ [Budynas \& Nissbett) and $K_{i} \approx 0.2$ for screws of standard proportions.

The torsional shear stress from the preload torque is estimated as:

$$
\tau_{t}=\frac{16 T_{i}}{\pi d_{t}^{3}}
$$

\subsection{Preload Equivalent Static Tensile Stress}

In order to correctly add the axial tensile stress to the bending stress, the stress planes and directions are shown in Figure 4. The two stresses are on the same plane and have the same directions as indicated in the equivalent cylinder, so an algebraic sum gives the combined effect of the stresses. Referring to Figure 5, it is observed that the direct shear stress and torsional stress act on perpendicular planes. In this case, a vector sum rule is used to obtain the combined effect of the stresses. Note that when the screw is in service, the torsional stress is zero.
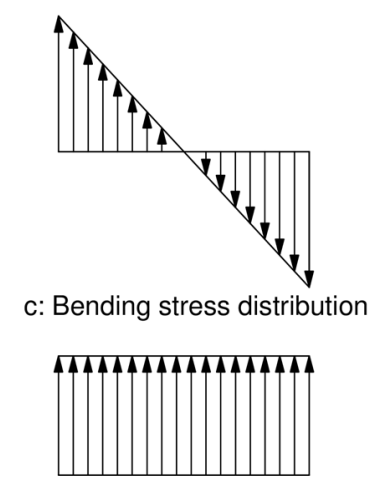

b: Bending stress distribution

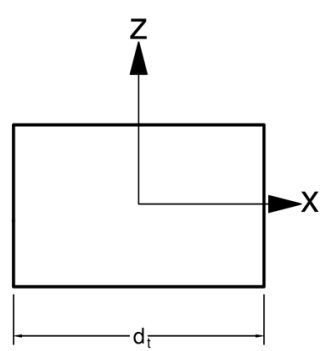

a: Equivalent cylinder

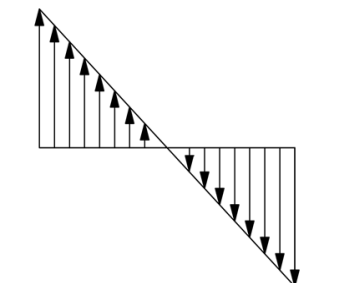

c: Torsional stress distribution

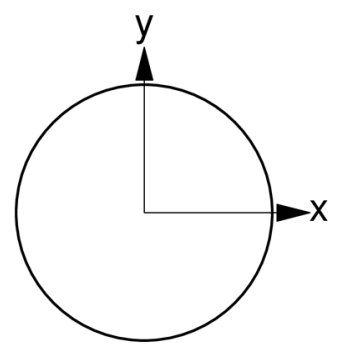

a: Equivalent cylinder
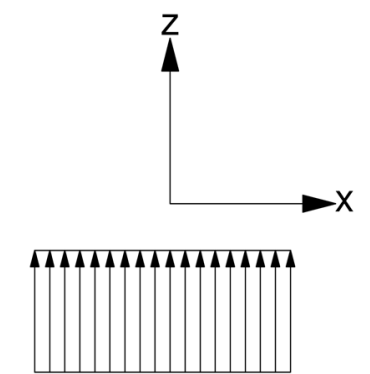

b: Direct shear stress distribu

Figure 4. Normal stresses in screw thread

Figure 5. Shear stresses in screw thread

Equivalent stress is obtained by combining stresses of different types together and a failure theory is required. For ductile materials such as assumed for screw fasteners, the distortion energy theory is the best based on experimental evidence (Norton, 2000). In a plane stress situation, normal (axial and bending) stresses and shear (direct shear and torsional) stresses operate and the equivalent stress is:

$$
\sigma_{t}=\sqrt{\sigma_{n}^{2}+3 \tau^{2}}
$$


Applying the above rule to Figs 4 and Fig 5, the pre-load equivalent stress is:

$$
\sigma_{t e}=\sqrt{\left(\sigma_{z}+\sigma_{b}\right)^{2}+3\left(\tau_{t}^{2}+\tau_{s}^{2}\right)}
$$

For elastic screw design $\sigma_{t e}$ must be at most equal to the yield strength of the screw material. Sometimes screws may fracture during preloading because the induced stresses exceed the ultimate strength of the screw material. Even when fracturing does not occur, there is still a risk of over-pre-tensioning if the induced stresses exceed the yield strength. In this situation, the screws are no longer linear-elastic and non-linear stress analysis applies. While the joint may function in operation, Hooke's law is no longer valid for such joints.

\subsection{Service Equivalent Static Tensile Stress}

When the joint is in service, it is under the influence of the external load $F_{b}$ and the preload torque is completely relieved (i.e., $\tau_{t}=0$ in Eq. (30)). The threads bear the transferred load from the external load through the contacts at the engagement points. For static analysis, the maximum thread load is used to estimate thread stresses. The stress equations for the preload force can be modified for the service load by substituting the maximum service load $F_{b}$ for the preload force $F_{i}$. Since the stresses are directly proportional to load in Eqs. (19), (21), and (24), the service equivalent static tensile stress may be estimated as:

$$
\sigma_{t s}=\alpha_{b} \sqrt{\left.\left(\sigma_{z}+\sigma_{b}\right)^{2}+3 \tau_{s}^{2}\right)} \quad \alpha_{b}=\frac{F_{b}}{F_{i}}
$$

The service load ratio $\alpha_{b}$, gives the ratio of service load to preload. It should be greater that unity. Higher values means the screw fastener is carrying a good proportion of the external load. Depending on the value of $\alpha_{b}, \sigma_{t s}$ could be smaller or greater than $\sigma_{t e}$, but each must be at most equal to the yield strength for elastic screw design.

\subsection{Fatigue Resistance}

Fatigue failure normally takes the form of brittle fracture at stresses well below the static strength of the materials (Hidgon, Osheen, Stiles, \& Weesa, 1967). About $80 \%$ to $90 \%$ of the failures of machine and structural members result from fatigue (Kravchenko, 1964; Sachs, 1999). The stress state in bending fatigue is appraised from the maximum and minimum stress values imposed on a member during one load cycle. The exact variation of the stress during the cycle does not seem to be particularly relevant (Kravchenko, 1964; Dieter, 1976). Fatigue damage is assessed using the mean and amplitude stress components.

\subsubsection{Axial Tensile Stresses}

The fatigue force components are $F_{m}$ and $F_{a}$ and these forces individually replaces $F_{i}$ in Eqs. (19), (21), and (24) in order to estimate each stress component. The mean and alternating axial tensile stresses on a thread are respectively, from Eq. (14):

$$
\sigma_{m z}=\frac{F_{m}}{A_{t}} \quad \sigma_{a z}=\frac{F_{a}}{A_{t}}
$$

\subsubsection{Direct Shear Stresses}

The mean and alternating direct shear stresses for the first thread are respectively from Eq. (14):

$$
\tau_{s m}=\frac{0.13 F_{m}}{A_{s}} \quad \tau_{s a}=\frac{0.13 F_{a}}{A_{s}}
$$

\subsubsection{Bending Stresses}

The mean and alternating bending moments on the first thread are respectively:

$$
M_{x m}=\frac{0.13 F_{m}\left(d_{p}-d_{r}\right)}{2} \quad M_{x a}=\frac{0.13 F_{a}\left(d_{p}-d_{r}\right)}{2}
$$

The mean and alternating bending stresses for the first thread are respectively:

$$
\sigma_{b m}=\frac{M_{m x}}{Z_{x}} \quad \sigma_{b a}=\frac{M_{a x}}{Z_{x}}
$$

Reversed axial fatigue strength is about $10 \%$ to $20 \%$ less than that of revised bending (Gope, 2014). That is, the load factor for axial fatigue load is in the range of 0.8 to 0.9 , so we will recommend 0.85 for design calculations. That means a unit reversed axial stress is about $85 \%$ of a unit reversed bending stress. Thus reversed axial stress damage is slightly less than that of reversed bending stress damage. Therefore, bending fatigue stress may be converted to axial 
fatigue stress by multiplying it with a factor of 1.175. For a screw thread, Eq. (35) ought to be corrected with this factor. That is:

$$
\begin{aligned}
& \sigma_{b m}=\frac{1.175 M_{m x}}{Z_{x}} \quad \sigma_{b a}=\frac{1.175 M_{a x}}{Z_{x}} \\
& \sigma_{m}=\sqrt{\left(\sigma_{z m}+\sigma_{b m}\right)^{2}+3 \tau_{s m}^{2}}
\end{aligned}
$$

Fatigue stress is greatly influenced by stress concentrations resulting from the presence of notches on components. When the region of stress concentration is small compared to the section resisting static load, ductile materials (e.g. low carbon and annealed steels) yield locally, limiting the stress in the region approximately to the yield strength of the material. No gross plastic deformation occurs; only strain hardening does (Shigley \& Mischke, 1996; Budynas \& Nissbett). This shows that ductile materials under static load are insensitive to stress concentration effects. Under fatigue loading, experimental studies indicate that stress concentration factors should be applied only to amplitude components of stress for ductile materials (Collins, Busby \& Staab, 2010). Thus ductile materials seem to respond to mean stresses as if they are "static stresses". The alternating stress component may be estimated as:

$$
\sigma_{a}=k_{\sigma} \sqrt{\left(\sigma_{z a}+\sigma_{b a}\right)^{2}+3 \tau_{s a}^{2}}
$$

When a tensile mean stress is present during a fatigue load cycle, the material fails at amplitude stress levels lower than the fatigue strength. Among popular models addressing this problems are the Gerber (Germany, 1874), Goodman (England, 1899), and Soderberg (USA, 1930) (Osakue, 2012). The Gerber model seems accurate and central based on experimental evidence (Norton, 2000), representing average behavior of ductile materials. The modified Goodman model is often used in design analysis because it is linear and more conservative than the Gerber model which is non-linear. The Soderberg model is linear but now largely of historical significance due to its overt conservatism. Because the Gerber model represents average behavior of ductile materials (Norton, 2000; Shigley \& Mischke, 1996), we prefer this model since it may be associated with $50 \%$ reliability in design. This is attractive because fatigue strengths are usually determined at $50 \%$ reliability and therefore, represents a very good fit.

In the Gerber fatigue design diagram of Figure 6; the fatigue strength of a material is on the vertical axis and the ultimate tensile strength is on the horizontal axis. The allowable design space has been divided into dynamic (section $\mathrm{OAB}$ ) and static (section $\mathrm{OBC}$ ) fatigue failure regimes (Osakue, 2012; Osakue, Anetor, \& Odetunde, 2012). A design point, such as point $\mathrm{D}$ in Figure 6 is defined by the coordinates $\left(\sigma_{m}, \sigma_{a}\right)$, which is associated with a load line OD. The line $\mathrm{OB}$ is the transition line between the two regimes and its slope is associated with the parameter $\eta_{t}$. Values of $\eta$ more than or equal to $\eta_{t}$ puts a design point in the dynamic fatigue space while values of $\eta$ less than $\eta_{t}$ puts a design point in the static fatigue space.

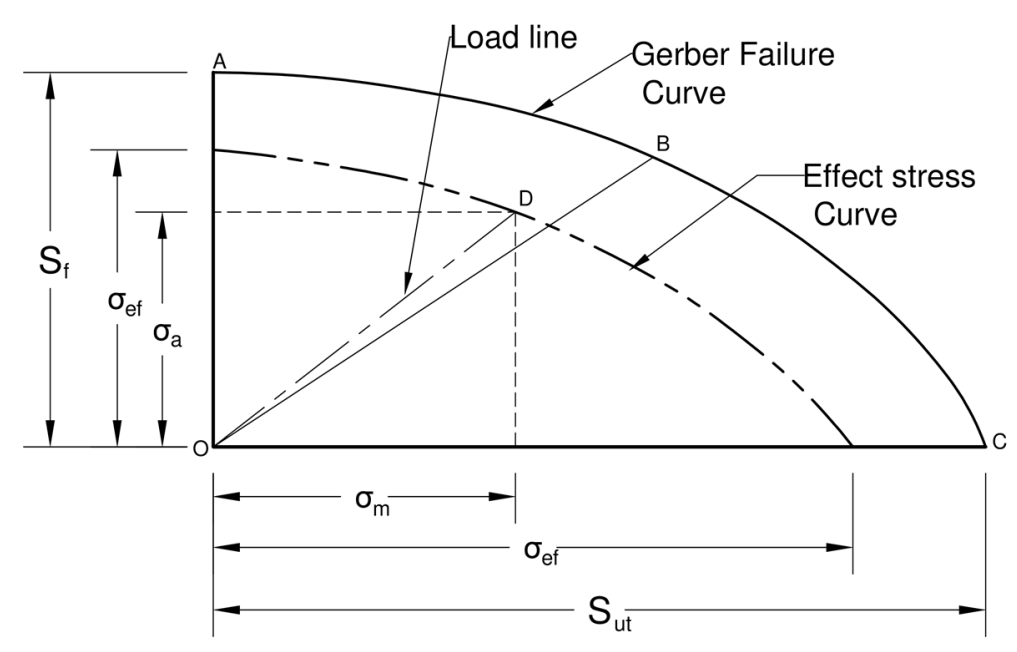

Figure 6. Gerber fatigue design diagram 
In Figure 6, the load line slope, fatigue regime discriminant factor, and fatigue strength are respectively, given (Osakue, 2012; Osakue, 2013) as:

$$
\eta=\frac{\sigma_{a}}{\sigma_{m}} \quad \eta_{t}=1.5 \psi_{s} \quad S_{f}=\psi_{s} S_{u t}
$$

The axial fatigue load type factor, fatigue size factor, (Gope, 2014) and fatigue ratio are obtained respectively, as:

$$
C_{a l}=1.4335 S_{u t}^{-0.0783} \quad C_{s z}=2.4 d_{t}^{-0.107} \quad \text { for } 3 \leq d_{t} \leq 51 \mathrm{~mm} \quad \psi_{s}=0.5 C_{a l} C_{s z}
$$

\subsubsection{Dynamic Fatigue: $\eta \geq \eta_{t}$}

In the dynamic regime, component failure will most likely result from the predominant influence of the amplitude stress. The mean stress is projected on the vertical axis and added to the amplitude stress to produce an effective amplitude stress. Failure occurs in this regime if the effective amplitude stress is equal to or more than the fatigue strength of a component material. In this regime, the effective alternating stress (Osakue, 2013) is:

$$
\sigma_{e f}=\frac{\sigma_{a}}{1-n_{m}^{2}} \quad n_{m}=\frac{\sigma_{m}}{S_{u}}
$$

Failure by dynamic fatigue mode is usually sudden, without prior warning. It is preferable to ensure that this failure mode is unlikely for screw fasteners. That is, the design factor for dynamic fatigue failure mode should be higher than those of other failure modes.

\subsubsection{Static Fatigue: $\eta<\eta_{t}$}

In the static fatigue regime, component failure will most likely result from the predominant influence of the mean stress. The amplitude stress can be projected on the horizontal axis and added to the mean stress to produce an effective mean stress. Failure occurs in this regime if the effective mean stress is equal to or more than the tensile strength of the material of a component. In this regime, the effective mean stress (Osakue, 2013) is:

$$
\sigma_{e f}=\frac{\sigma_{m}}{\sqrt{1-n_{a}}} \quad n_{a}=\frac{\sigma_{a}}{S_{f}}
$$

It is anticipated that failure by static fatigue mode is largely similar to ductile fracture but not exactly the same due to the presence of the alternating stress of low amplitude. Screw deformation manifesting in extended length and gross reduction in diameter is expected. Such should allow increased vibrations which could serve as warning of impending failure or breakdown. Therefore, screw preload tension should be set high enough to promote this mode of fatigue failure.

Usually the value of $n_{m}$ (Eq. (41b)) or $n_{a}$ (Eq. (42b)) will be less than unity. If either value is very close to unity, then failure is inevitable. Hence during design verification, a different size screw fastener should be selected and verified if their values are close to unity.

\subsection{Crushing Stress}

The crushing stress is developed on the contacting surfaces of the screw and nut threads. Though the thread surfaces are inclined, the projected area of the contact surface will be used for its estimate. The average crushing stress is obtained as:

$$
\sigma_{c}=\frac{2 \times 0.13 F_{b}}{\pi d_{t}\left(d_{o}-d_{r}\right)}
$$

\section{Design Factors For Elastic Screws}

The purpose of safety or design (preferred) factor is to guard against uncertainty in load, geometry, material properties, and other design assumptions. The load is by far the most uncertain design parameter (ME 452). Both the preload force and external service load must be considered in screw fastener design. In addition to the above uncertainties, accuracy of computational models and failure criterion must be considered. Therefore the minimum acceptable design factor should adequately account for these uncertainties. It is perhaps more realistic to estimate minimum acceptable design factor on a statistical basis, rather than selecting an arbitrary value. 


\subsection{Static Yield Design Factors}

The static stresses considered above are the preload and service load equivalent stresses. The preload static yield design factor is:

$$
n_{y p}=\frac{S_{y t}}{\sigma_{t e}}
$$

The service load static yield design factor is:

$$
n_{y s}=\frac{S_{y t}}{\sigma_{t s}}
$$

When a stress on a ductile material reaches the yield strength, a permanent set is created and the material cannot regain its original size and shape if the stress is relieved. It is unsafe to load screw fasteners up to the yield point of the material because a permanent set or plastic deformation occurs at the yield point. To ensure that screw fasteners operate within the elastic range; a proof strength is used in their design (ME 452). The proof strength is approximately equal to the proportional limit stress of the material (Shigley \& Mischke, 1996). Therefore, a minimum design factor for static yield is:

$$
n_{y o}=\frac{S_{y t}}{S_{p}}
$$

For an adequate design against static yield resistance:

$$
n_{y p} \geq n_{y o} \quad n_{y s} \geq n_{y o}
$$

\subsection{Fatigue Design Factors}

\subsubsection{Dynamic Fatigue}

This is the high alternating stress regime. Stresses in this regime are in the elastic range because fatigue strength is usually lower that the yield strength for ductile materials. The maximum stress allowed is the fatigue strength of the screw material, so the design factor is:

$$
n_{f}=\frac{S_{f}}{\sigma_{e f}}
$$

For an adequate design:

$$
n_{f} \geq n_{o}
$$

\subsubsection{Static Fatigue}

The alternating stress value is low in this regime of the design diagram and stresses may be in the plastic range. The failure stress is the tensile strength of the screw material, so the design factor is:

$$
n_{f}=\frac{S_{u t}}{\sigma_{e f}}
$$

In elastic screw fasteners design, Hooke's law is assumed which implies stresses must be in the linear-elastic range. The maximum stress allowed in the linear-elastic range is the proof strength. Therefore, a minimum design factor for this regime is the ratio of tensile strength to the proof strength. For an adequate design:

$$
n_{f} \geq \max \left(n_{u} ; n_{o}\right) \quad \text { where } n_{u}=\frac{S_{u t}}{S_{p}}
$$




\subsection{Separation Load Design Factor}

Screw joints should be designed to operate with adequate preload so that joint separation does not occur. However, if the external load is large enough, the compression from the preload can be completely removed. If this happens, the whole external load will be carried by the screw fastener and the clamped members would bodily separate. In a pressurized system, this will lead to leakage. In non-pressurized systems, violent vibrations and break down could occur. To preclude joint separation, the initial preload should be at least equal to the separation load of Eq. (8). If $n_{s}$ is the design factor for separation load, then:

$$
n_{s}=\frac{F_{i}}{F_{e}\left(1-c_{b}\right)}
$$

For an adequate design:

$$
n_{s} \geq n_{o}
$$

\subsection{Crushing Stress Design Factor}

The crushing stress design factor is:

$$
n_{c}=\frac{S_{y t}}{\sigma_{c}}
$$

For an adequate design:

$$
n_{c} \geq n_{o}
$$

According to Schmid, Hamrock \& Jacobson (2014), the design factor for properly preloaded screw fasteners cannot be greater than 2.4 and is usually below 2.0 . That is: $n_{o}<2.5$. A design factor less than unity represent a case of under-design and failure is almost certain if the design is implemented. This is risky and must be avoided in all failure modes in screw fastener design.

\section{Applications of Design Approach}

The equations presented in the previous sections were coded in Microsoft Excel for computational efficiency. The spreadsheet has two pages; the first page is used for design sizing and summary of a screw fastener while the second page is used for design verification. Data for design such as external load, material specification, etc. are provided in the first page. The stress concentration factor is determined and used to estimate the required tensile stress area of the screw. A tentative screw outside diameter and pitch selection is made from design sizing estimate and used in the second page for design verification. In the second page, the stiffness of the screw fastener and the stiffness of the clamped parts are estimated. Then the crushing, static and fatigue stresses are determined. The design factors are estimated so that the adequacy of the screw fastener design can be judged. Iteration during design verification can be done by changing the value of the screw fastener pitch and or its outside diameter. Also, the preload tension can be varied during design verification.

Two design examples are considered with the design approach presented in the previous sections. The first example is focused on the design verification of a chosen previous design. The example is modified by changing the preload tension value. Also a change of the coarse pitch value of $2.3 \mathrm{~mm}$ to $1.5 \mathrm{~mm}$ for fine series is made so as to investigate the influence of screw pitch on design factors. The second example involves both sizing and verification tasks so as to present a complete demonstration of the application of the design approach being proposed. The problem statements in the examples have been paraphrased and the design parameters have been converted to metric units by the authors. A minimum design factor of 1.25 is assumed for the examples since preload torque can vary routinely by $\pm 25 \%$.

\subsection{Design Examples}

\subsubsection{Example 1a}

Six 5/16-11 UNC screw fastener of SAE Grade 5 are used in an ASTM Grade 25 cast iron vessel under a total load of $160 \mathrm{kN}$. Initial study suggests $k_{b}=0.912 \mathrm{MN} / \mathrm{mm}$ and $k_{c}=1.567 \mathrm{MN} / \mathrm{mm}$. Determine the design factors assuming the preload is $64 \mathrm{kN}$ (Budynas \& Nissbett, p. 442 - 444 ).

Data in Example 1a were input into the Excel sheets and Table 1 presents the evaluated design factors using the stress capacity models developed. Column 1 in the table summarizes the design factors of interest, column 2 gives the 
minimum acceptable values for the design factors, column 3 are the results for the previous design, while column 4 gives values for a modified design. Current design modifies the previous one by reducing the preload tension from 64 $\mathrm{kN}$ to $35 \mathrm{kN}$. No change in screw specification is made.

Table 1. Example 1 Design Factors

\begin{tabular}{llll}
\hline Design Factor & Desired Minimum Value & Budynas \& Nissbett & Modified Design \\
\hline Preload static yield & 1.09 & 0.77 & 1.42 \\
Service load static yield & 1.09 & 0.68 & 1.12 \\
Separation load & 1.25 & 3.80 & 2.08 \\
Static fatigue & 1.41 & 0.91 & 1.57 \\
Dynamic fatigue & 1.25 & 0.73 & 1.78 \\
Crushing stress & 1.25 & 4.04 & 6.66 \\
\hline
\end{tabular}

\subsubsection{Example 1b}

If the bolts in Example 1a are replaced with six M16×1.5 fine pitch series of SAE Grade 5, what are the design factors assuming the preload is $64 \mathrm{kN}$.

Data in Examples 1a were input into the Excel sheets and the screw pitch changed to $1.5 \mathrm{~mm}$. Table 2 compares design factors of fine pitch with those of coarse pitch from Example 1a. The last column of Table 2 shows the percentage differences between coarse and fine pitch solutions.

Table 2. Design Factors for Coarse and Fine Pitch Options of Example 1a

\begin{tabular}{llll}
\hline Design Factor & Coarse Pitch & Fine Pitch & \% Difference \\
\hline Preload static yield & 0.77 & 0.86 & 11.69 \\
Service load static yield & 0.68 & 0.78 & 14.71 \\
Separation load & 3.80 & 3.80 & 0 \\
Static fatigue & 0.91 & 0.82 & -9.89 \\
Dynamic fatigue & 0.73 & 0.44 & -39.73 \\
Crushing stress & 4.04 & 2.80 & -30.69 \\
\hline
\end{tabular}

\subsection{Example 2}

Two bolts are used to support an external tensile load of $10 \mathrm{kN}$. For a preliminary design, ISO class 4.6 bolts are specified and initial estimate indicates $k_{c}=4 k_{b}$ can be expected. The maximum root stress is to be less than $65 \%$ of the minimum yield strength of the bolt material and the joint cannot separate. Determine the minimum required preload to ensure that the joint does not separate and the size of bolt required (Collins, Busby \& Staab, 2010; p. $501-$ 502).

Data in Example 2 were input into the Excel sheets and Table 3 presents the results of the design sizing task.

Table 3. Design Sizing Results for Example 2

\begin{tabular}{lll}
\hline Design Parameter & Collins, Busby \& Staab (2010) & Current Design \\
\hline Tensile stress area-estimate $\left(\mathrm{mm}^{2}\right)$ & 20.83 & 50.89 \\
Tensile stress area-chosen $\left(\mathrm{mm}^{2}\right)$ & 34.7 & 59.5 \\
Screw outside diameter-chosen $(\mathrm{mm})$ & 8 & 10 \\
Screw pitch-chosen $(\mathrm{mm})$ & 1.25 & 1.5 \\
\hline
\end{tabular}

Table 4 compares design factors from the preliminary design results of (Collins, Busby \& Staab, 2010 with the current design results. Column 1 in the table summarizes the design factors of interest, column 2 gives the minimum acceptable values, column 3 are the results for the previous design, while column 4 gives values for the current design. Current design uses the sizing and verification approach presented in this paper. 
Table 4. Design Factors for Example 2

\begin{tabular}{llll}
\hline Design Factor & Desired Minimum Value & Collins, Busby \& Staab, (2010) & Current Design \\
\hline Preload static yield & 1.07 & 1.14 & 1.25 \\
Service load static yield & 1.07 & 0.93 & 1.09 \\
Separation load & 1.25 & 1.00 & 1.45 \\
Static fatigue & 1.78 & 2.02 & 2.38 \\
Dynamic fatigue & 1.25 & 3.37 & 5.36 \\
Crushing stress & 1.25 & 6.11 & 6.78 \\
\hline
\end{tabular}

\section{Discussions}

In Table 1 and from column 3, we note that the static yield design factors are 0.77 and 0.68 for preload and service load, respectively. These values are less than unity, representing a case of under-design in static yield failure modes. Without changing the specification of the screw fastener, the preload tension was reduced by $62.76 \%$, and the static yield design factors changed to 1.42 and 1.12 for preload and service load, respectively. This shows that the under-design condition resulted from high preload tension and if that solution was implanted, it would mean the screw yielded before it was put in service. That is, a yielded and strain-hardened screw fastener would have been put into service! Also, both static and dynamic fatigue design factors are lower than unity in the previous design which makes fatigue failure very likely in service. The joint separation design factor is rather very high, so no bodily separation of parts is anticipated in service in the previous design. This appears to be a case of over-design in this failure mode. In column 4, the modified design show improved design factors, and meet all minimum values desired. Therefore, arbitrary specification of high preload tension may lead to putting an over-strained screw fastener in service.

The entries in the last column of Table 2 are the results for M16×1.5, a fine series metric thread. It is noted that the fine pitch screw shows some improvement in static stress design factors but worse off in fatigue stress design factors than the coarse pitch thread generally. The common notion is that fine pitch threads should perform better than coarse pitch threads because they have higher tensile area values compared to coarse threads. Under the same load value, axial tensile stress in fine pitch threads should be lower than that in coarse pitch threads. If it is only axial tensile stress that is generated in screws, this will be true. However, the presence of shear and bending stresses is undeniable, so their influence on load or stress capacity should not be ignored. While fine pitch threads may have larger tensile stress area as indicated by the improvement in static stress design factors, the shear stress area could be smaller than that of coarse pitch due to smaller root thread thickness. Similarly, the section modulus used in bending stress estimate is smaller for fine pitch thread than coarse pitch thread. The reduction in axial tensile stress for fine pitch screws may be offset by increases from direct shear and bending stresses. Hence when direct shear and bending stresses are considered in addition to axial tensile stress, fine pitch threads may come out worse off as indicated by the fatigue stress design factors. The bending stress influence may be more than that of the shear stress.

Table 3 shows that screw size $M 10 \times 1.5$ is suggested by the design approach being proposed in this paper. This size is slightly larger, but very much close to the previous design solution of $M 8 \times 1.25$. The proposed solution is thus slightly conservative with respect to the previous one. It should be noted that the previous solution did not incorporate stress concentration value which was applied in the new solution. In Table 4 columns 3 and 4, design verification indicates the previous solution and new solution has a minimum design factor of 0.93 and 1.09 , respectively for the service load. A case of under-design condition is therefore indicated for the previous design, since the service static stress design factor is less than unity. This means that the service load is very likely to induce plastic strain in the screw fastener if that solution was implemented. This presents the possibility of the screw fastener yielding in service, leading to lower clamping force. The situation is worsened because of the unity value of the separation load design factor. Problems in service should, therefore, be anticipated from possible overload. Fatigue design factors are high, so fatigue resistance is good. In column 4, the design factors for the new design are shown. Clearly, the issues associated with the previous design are largely eliminated.

In the Examples considered, crushing stress design factors are relatively high, suggesting that this failure mode is not a critical one in them. So neglecting it may be justified in these cases, however, the number of Examples is too few to generalize. Quantifying the crushing stress has helped in concluding that it is not critical in these Examples. Without an estimate, it is virtually impossible to make any rational conclusion.

The main short coming of the previous two design Examples cited has to do with the neglect of shear and bending stresses. As noted above, this resulted in under-design condition for some failure modes. Putting screw fasteners with under-design condition in any failure mode into service is risky and would mean early failure at the least. This may 
explain why some screw fasteners failed in the past. Therefore, we recommend that shear and bending stresses should always be considered in screw design.

\section{Conclusions}

An approach is proposed for elastic screw fastener design so that expected stresses are at most equal to the proof strength at preload and in service. When the load is removed, elastic screw fasteners regain their original size and shape, behaving like springs. Models for equivalent and or effective stresses are developed for screw preload, maximum service load, crushing, static, and dynamic fatigue failure modes. Design factors are derived for these failure modes and are used to assess design adequacy during design verification task. Two illustrative design examples are used to demonstrate applications of the approach. The results indicate that ignoring direct shear and bending stresses can lead to under-design in some screw fastener failure modes.

The conclusions from this study are summarized as:

- Direct shear and bending stresses contributions in screw fasteners can lead to higher equivalent stresses that may cause failure at preloading or in service. Therefore, we recommend that shear and bending stresses should always be considered in screw fastener design.

- Equivalent stresses in fine pitch screws are not necessarily lower than those of coarse pitch screws when direct shear and bending stresses are considered. The reduction in axial tensile stress for fine pitch screws can be offset by increases in direct shear and bending stresses.

- The static yield design factor should be such as will take care of the uncertainty in external load, preload, and screw material yield strength. The preload uncertainty is ordinarily high.

- Yield at preloading should be avoided. Therefore arbitrary specification of high preload stress should be avoided. Imposed stresses on elastic screw fasteners should never be higher than the proof strength during pre-tensioning or in service.

- Fatigue failure of a screw is greatly influenced by the preload tension applied at setup or assembly.

- The minimum preload tension should be equal to the joint separation load which is slightly less than the external load in hard joints.

- Too high preload tension should be avoided to prevent static yield of screw fastener either during pre-tensioning or in service.

- Screw fasteners should be designed to fail first in static fatigue mode before separation of joint whenever possible.

- Where practical, optimum design should be preferred. For optimum design, the static fatigue and joint separation design factors should be nearly equal. It is preferable to make the joint separation design factor slightly higher to avoid bodily separation of parts in service.

- Dynamic fatigue design factor should be the highest to prevent screw fasteners from failing in this mode before other modes of failure.

\section{Acknowledgements}

The authors gratefully acknowledge that this study was supported in parts with funds from COSET Research Fund and the University Faculty Development Fund of Texas Southern University, Houston, Texas.

\section{References}

Bausbacher, E., \& Hunt, H. (1993). Process Plant Layout and Design, PTR Prentice Hall, Upper Saddle River, New Jersey.

Berezovsky, Y., Chernilevsky, D., \& Petrov, M. (1988). Machine Design, MIR, Moscow, p. 416.

Bhandari, V. B. (2010). Design of Machine Elements, 3rd ed., McGraw Hill, India. Bhandari, ME, p. 257

Budynas, R. G., \& Nissbett, J. K. (n.d.). Shigley's Mechanical Engineering Design (9th ed.). McGraw Hill Education.

Childs, P. R. N. (2004). Mechanical Design (2nd ed.). Elsevier, New York.

Collins, J. A., Busby, H., \& Staab, G. H., (2010). Mechanical Design of Machine Elements and Machines: A Failure Prevention Perspective (2nd ed.). John Wiley and Sons, New York Collins, p. 508 Collins, p. 495

Dieter, E. G. (1976). Mechanical Metallurgy (2nd ed., Chap. 12). New York: McGraw-Hill.

FEDS Rev.3.4-2009, Bolted Joint Design. Retrieved from http://.www.engineer@fastenal.com 
Gope, P. C. (2014). Machine Design: Fundamentals and Applications, PHI Learning, Delhi.

Hidgon, A., Ohseen, E. H., Stiles, W. B., \& Weesa, J. A. (1967). Mechanics of Materials (2nd Ed.). New York, Wiley \& Sons, Chap. 10.

Hudgins, A., \& James, B. (2014). Fatigue of Threaded Fasteners, Advanced Materials and Processes (pp. 18 - 22).

Korsakov, V. S., \& Zamyatin, V. K. (1987). Assembly Practice in Machine Design, MIR, Moscow, p. 137.

Kravchenko, P. Y. E. (1964). Fatigue Resistance. New York, Pergamon.

ME 452: Machine Design II, Solution to Homework Set 10. Retrieved from https://www.coursehero.com/file/ 12146287/hw10solFall2013/

Norton, R. L. (2000). Machine Design: An Integrated Approach, Prentice-Hall, Upper Saddle River, New Jersey.

Osakue, E. E., Anetor, L., \& Odetunde, C. (2012). A Generalized Linearized Gerber Fatigue Model. Machine Design, $4,1-10$.

Osakue, E. E., Anetor, L., \& Odetunde, C. (2015). Reliability-based Component Design, Proceedings of International Mechanical Engineering Congress and Exposition 2015 MECE, Paper Number IMECE2015-50700, November 13-19, Houston, Texas, USA.

Osakue, E. E. (2012). A Linearized Gerber Fatigue Model. International Journal of Modern Engineering, 12(1), 64-72.

Osakue, E. E. (2013). Probabilistic Design with Gerber Fatigue Model. Mechanical Engineering Research, 1, 99 -117. https://doi.org/10.5539/mer.v3n1p99

Sachs, N. (1999). Root Cause Failure Analysis -Interpretation of Fatigue Failures. Reliability Magazine.

Schmid, S. R., Hamrock, B. J., \& Jacobson,B. O. (2014). Fundamentals of Machine Elements (3rd ed.). CRC Press, New York.

Shigley, J. E., \& Mischke, C. R. (1996). Standard Handbook of Machine Design. McGraw-Hill, New York. Shigley Shigley \& Mischke, 1996 HB, p. 12.8.

Zahavi, E. (1992). The Finite Element Method in Machine Design. Prentice Hall, Eaglewood Cliffs, N. J.

\section{Nomenclature}

$A_{s}-\quad$ thread root shear area

$A_{t}-\quad$ screw tensile stress area

$C_{a l}-\quad$ axial fatigue load factor

$C_{s z}-\quad$ fatigue size factor

$d_{o}-\quad$ outside or nominal screw diameter

$d_{p}-\quad$ pitch diameter

$d_{t}-\quad$ tensile stress diameter

$d_{r}-\quad$ root diameter

$p_{t}-\quad$ thread pitch

$t_{1}-\quad$ thickness of member 1

$t_{2}-\quad$ thickness of member 1

$c_{b}-\quad$ screw stiffness factor

$k_{c}-\quad$ stiffness of clamped members

$k_{b}-\quad$ stiffness of screw fastener

$k_{\sigma}-\quad$ stress concentration factor

$F_{1}-\quad$ contact force at thread 1

$F_{2}-\quad$ contact force at thread 2

$F_{i}-\quad$ initial tension load

$F_{b \max }-$ maximum load on screw
$S_{u t}-\quad$ ultimate tensile strength

$n_{c}-\quad$ crushing stress design factor

$n_{m}-\quad$ mean fatigue stress factor

$n_{a}-\quad$ alternating fatigue stress factor

$n_{y o}-\quad$ minimum static yield design factor

$n_{y p}-\quad$ preload static yield design factor

$n_{y s}-\quad$ service load static yield design factor

$n_{f}-\quad$ fatigue stress design factor

$n_{s}-\quad$ separation load design factor

$n_{u}-\quad$ tensile strength factor

$n_{o}-\quad$ minimum acceptable design factor

$\alpha_{b}-\quad$ service load ratio

$\alpha_{p}-\quad$ allowable preload stress factor

$\phi$ - lead angle

$\mu_{0}-\quad$ lead angle factor

$\mu_{t}-\quad$ thread friction coefficient

$\mu_{c}-\quad$ collar friction coefficient

$\mu_{o}-\quad$ thread lead angle factor

$\mu_{t e}-\quad$ effective thread friction coefficient 


$\begin{array}{llll}F_{b \min }- & \text { minimum load on screw } & \varphi- & \text { axial plane half-thread angle } \\ F_{m}- & \text { mean axial load on screw } & \sigma_{m}- & \text { equivalent mean tensile stress } \\ F_{a}- & \text { alternating axial load on screw } & \sigma_{a}- & \text { equivalent alternaring stress } \\ F_{e m}- & \text { mean external load on joint } & \sigma_{e f}- & \text { service effective fatigue stress } \\ F_{e a}- & \text { alternating external load on joint } & \sigma_{b}- & \text { bending tensile stress } \\ F_{e}- & \text { maximum external load on joint } & \sigma_{n}- & \text { normal stress } \\ F_{e}^{\prime}- & \text { minimum external load } & \sigma_{t}- & \text { tensile stress } \\ F_{e}- & \text { maximum external load } & \sigma_{t e}- & \text { preload equivalent static tensile stress } \\ l_{a}- & \text { bending moment arm } & \sigma_{t s}- & \text { service equivalent static tensile stress } \\ Z_{x}- & \text { section modulus } & \sigma_{x m}- & \text { mean bending tensile stress } \\ b- & \text { circumference of equivalent cylinder } & \sigma_{x a}- & \text { alternating bending tensile stress } \\ h- & \text { thread root thickness } & \sigma_{z m}- & \text { mean axial tensile stress } \\ T_{i}- & \text { preload torque } & \sigma_{z a}- & \text { alternating axial tensile stress } \\ F_{i}- & \text { preload force } & \tau- & \text { shear stress } \\ K_{i}- & \text { preload torque factor } & \tau_{s}- & \text { direct shear stress } \\ M_{x m}- & \text { mean bending moment } & \tau_{s m}- & \text { mean direct shear stress } \\ M_{x a}- & \text { alternating bending moment } & \tau_{s a}- & \text { alternating direct shear stress } \\ p_{t}- & \text { thread pitch } & \tau_{t}- & \text { torsional stress from preload torque } \\ S_{f}- & \text { service fatigue strength } & \eta- & \text { load line slope factor } \\ S_{p}- & \text { proof strength } & \eta_{t}- & \text { load line slope transition factor } \\ S_{y t}- & \text { tensile yield strength } & \psi_{s}- & \text { service fatigue ratio }\end{array}$

\section{Copyrights}

Copyright for this article is retained by the author(s), with first publication rights granted to the journal.

This is an open-access article distributed under the terms and conditions of the Creative Commons Attribution license (http://creativecommons.org/licenses/by/4.0/). 